\title{
A pilot study of death competency amongst health workers in the Uthukela District in KwaZulu-Natal
}

\author{
P Brysiewicz, M Curationis, School of Nursing, University of Kwa-Zulu Natal \\ PA Mclnerney, PhD, School of Nursing, University of Kwa-Zulu Natal
}

\section{Abstract}

\section{Aim:}

The aim of this study was to investigate the registered nurses abilities to cope with the death of their clients and to determine if there was any improvement after attending a workshop designed to address this issue.

\section{Null hypothesis:}

Using the Coping with Death Scale by Bugen (19801981 ) cited in Neimeyer (1994), respondents' pre-test scores are equal to their post-test scores.

\section{Methodology:}

An exploratory survey was used to investigate the registered nurses' death competencies before and after the scheduled workshops. Although these workshops were initially planned for registered nurses, a great variety of health workers (nurses, pharmacists, oral hygienists, physiotherapists and HIV community workers) expressed interest and were thus accommodated in the workshops. Data were collected from the Death Education Workshops held at three sites, and fifty-one respondents completed the questionnaire before the workshop and fifty-six on completion of the workshop. The tool that was used in this research was Bugen's (19801981) Coping with Death Scale, cited in Neimeyer (1994). This scale consists of 30 items assessing the participant's sense of competence in handling death and their concrete knowledge concerning preparation for death.

\section{Findings:}

Analysis of the pre and post tests revealed a move from a neutral stance to one where the respondents tended to have a more definite opinion about the statement. This was usually towards agreeing with the statement. Applying the two sampled T-Test to compare the scores of the two related groups (that is the pre-workshop and post-workshop variables), the results yielded were $t$ $=0.00,95 \%$ confidence level. Thus there was a significant difference between the two groups, and the null hypothesis is therefore rejected.

\section{Introduction}

Trauma in the province of KwaZulu-Natal is considered to be a large problem with violent deaths (that is non-natural deaths due to road traffic collisions, gunshots etc) accounting for a large number of the fatalities. These fatalities are usually young people in the prime of their lives (Meumann \& Peden, 1997:3). Road traffic collisions result in approximately 11 deaths per 100 million kilometers travelled, which is about ten times that reported in developed countries (van der Spuy, 1998:1). Pedestrian road traffic collisions account for approximately $40 \%$ of the annual road mortality in South Africa (van der Spuy, 1998:2). During 1997 a total of 610 children ( () to 18 years old) were killed and another $\mathbf{5 5 0 7}$ were non-fatally injured in traffic collisions involving pedestrians (Venter, 1998:8). The incidence of HIV/AIDS in South Africa is increasing at an alarming rate. It is estimated that approximately two thirds of the 34 million peo- ple infected with HIV/AIDS worldwide, live in Sub-Saharan Africa (MRC, 2000:22).

Due to the large number of clients dying on a daily basis health workers are often expected to cope with the dying or dead clients and their families. This can be a challenging and stressful event for the health workers. Regular exposure to this stress may lead to the development of various stress disorders if the health workers are not given sufficient support. The actions taken by the health workers play a large role in the bereavement outcomes for the families (Wright, 1996:1) and thus investigating their abilities to cope with death is essential.

Workshops were initiated by the district administrators due to concerns raised by the Uthukela district management regarding the number of deaths being experienced in the hospitals and clinics. Management was concerned that they were not addressing the needs or concerns of the staff 
working with these clients. Originally these workshops were planned for registered nurses but due to the interest expressed by other health workers the workshops included other categories of nurses, physiotherapists, pharmacists, oral hygienists and HIV community workers.

\section{Purpose}

The purpose of this research was to conduct a survey amongst health workers in the Uthukela District in KwaZuluNatal in order to establish their ability to cope with the death of their clients.

\section{Null hypothesis}

Using the Coping with Death Scale by Bugen (1980-1981) cited in Neimeyer (1994), respondents' pre-test scores are equal to their post-test scores.

\section{Objectives}

The objectives of this research were to:

- Investigate the health workers abilities to cope with the death of clients.

- Determine whether the health workers' abilities to cope with death had altered in any way after attending the workshop.

\section{Significance of the research}

This research will establish whether there is a need to carry out death education workshops in this district. It will also establish whether the current workshops being offered are relevant to the needs of the workshop participants, that is, if they aid in improving the participants' death competencies or not.

\section{Definition of terms}

\section{Death competency}

Death competency is "a construct that represents a range of human skills and capabilities in dealing with death, as well as our beliefs and attitudes about these capabilities" (Robbins, 1994, 161).

\section{Health workers}

Within this study this term was used to refer to the nurses (registered nurses, enrolled nurses, enrolled nursing assistants), pharmacists, HIV community workers, oral hygienists and physiotherapists involved as participants in the workshops.

\section{Ethical considerations}

Permission to carry out the research was obtained from the district's Research Committee and the district administration. One of the researchers explained the research project to the respondents, prior to handing out the questionnaire at the beginning and at the end of the one-and-a-half day workshop. The researchers ensured that the respondents were aware of the right to refuse to participate, and of the right to withdraw from the research at any time. The handing back of completed questionnaires to the researchers was taken as consenting to participate. The questionnaires were completed anonymously and the data could not be traced back to the individuals.

\section{The workshops}

A one-and-a-half day workshop was held on three separate occasions in three different areas of the Uthukela District in KwaZulu-Natal. The programme of the workshop broadly dealt with the following issues:

- $\quad$ Profile of deaths in the area

- Individual views of loss, death and dying

- $\quad$ Spirituality, cultural beliefs and customs regarding death and dying

- $\quad$ Dealing with the family and breaking bad news

- Therapeutic interventions in order to care for the client, relatives and the health workers

- Support and counseling for the health workers

\section{Research design}

This pilot study, using an exploratory survey, was used to investigate the health workers death competencies before and after the scheduled workshops.

\section{The sample and setting}

Registered nurses working in three hospitals and in various Primary Health Care clinics in the Uthukela District either volunteered to attend the workshop or were approached by their superiors. Three separate workshops took place at different time periods in three centres in the Uthukela District. The researchers had anticipated a sample of registered nurses but a number of respondents from a wide variety of fields expressed much interest in attending the workshops, after hearing about them informally, and were thus accommodated. The sample included the nurses (registered nurses, enrolled nurses, enrolled nursing assistants), pharmacists, HIV community workers, oral hygienists and physiotherapists.

\section{The questionnaire}

The tool that was used in this research was Bugen's (19801981) Coping with Death Scale, cited in Neimeyer (1994). This scale consists of 30 items assessing the participant's sense of competence in handling death and their concrete knowledge concerning preparation for death. The respondents were asked to rate their agreement or disagreement on a five point Likert-type scale, with 1 representing 'do not agree at all", 3 being "neutral" and 5 "agree completely". A sheet attached to the questionnaire also asked for biographical data from the respondents. 


\section{Validity and reliability}

Bugen's Coping with Death Scale (1980-1981) was found by Robbins (1994) to be both internally consistent and reliable. Neimeyer (19971998:102) reported that this scale displayed internal consistency and testretest reliability as well as construct validity.

\section{Data collection}

Data were collected from the health workers attending the Death Education Workshops at the three venues. The respondents were asked to complete the questionnaire on the day of the workshop, prior to starting, and then again at the end of the one and a half day workshop. Fifty-one respondents completed the questionnaire before the workshop and fifty-six on completion of the workshop. The reason for the difference between the two groups is that some respondents arrived late on the first day when the workshop had already commenced and the questionnaire had already been administered.

\section{Data analysis}

Data analysis was carried out using the Statistical Package for Social Sciences (SPSS) version 11. The data were summarized using descriptive statistics, and the significance of the workshop results were analysed using paired samples

T-test.

\section{Discussion of findings}

Applying the two sampled T-Test to compare the scores of the two related groups (that is the pre-workshop and post-workshop variables), the results yielded were $t=0.00,95 \%$ confidence level. Thus there was a significant difference with the two groups, and the null hypothesis is therefore rejected.

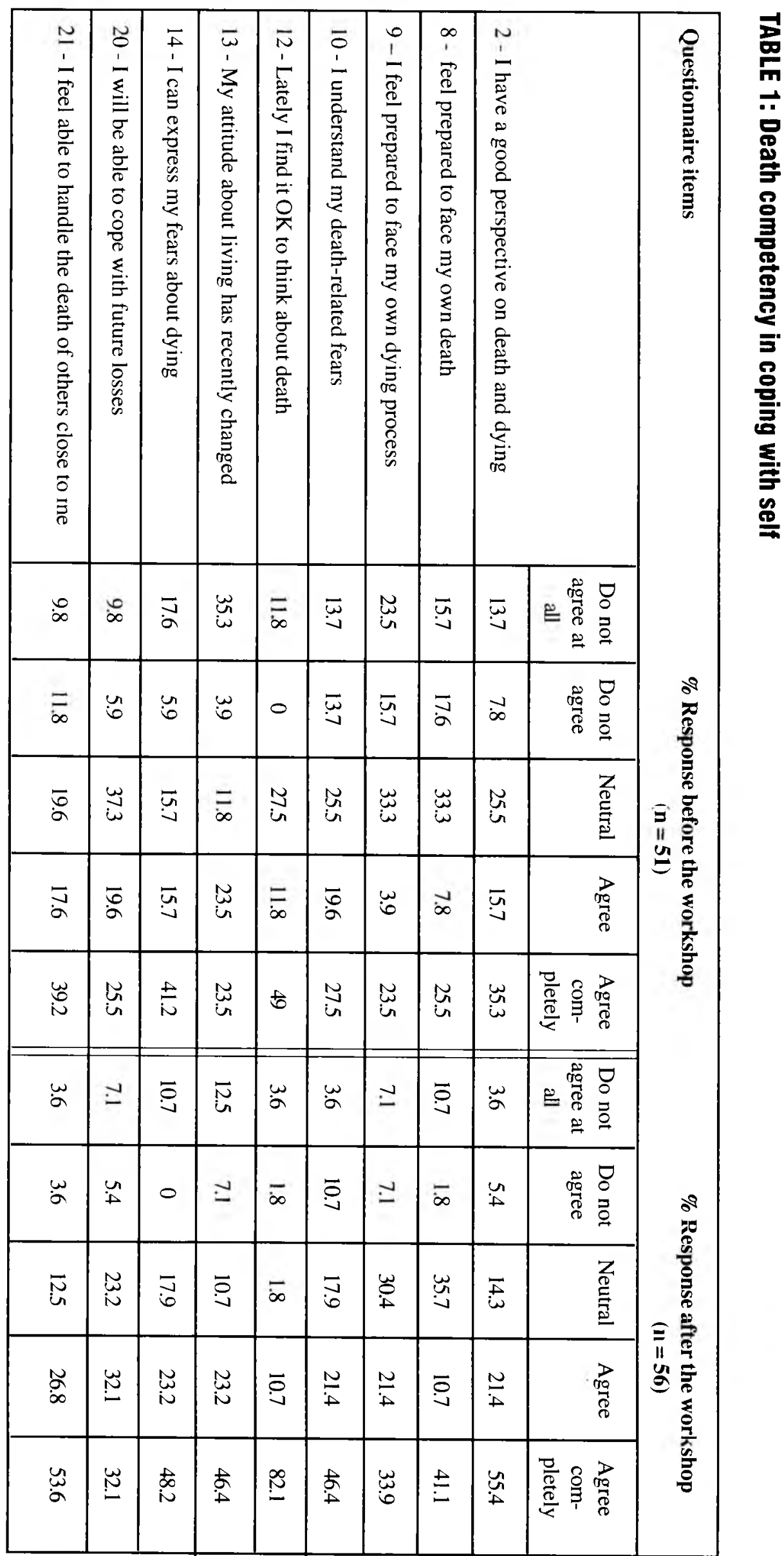

\section{Neutral responses}

The findings after the workshop generally showed a move from a neutral stance to one where the respondents tended to have a more definite opinion. This usually was towards agreeing with the statement in the questionnaire. Before 


\begin{tabular}{|c|c|c|c|c|c|c|c|}
\hline \multirow{5}{*}{ 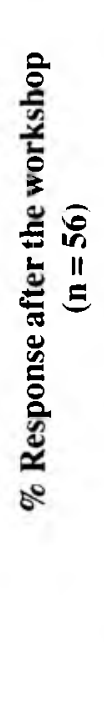 } & 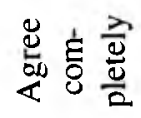 & ชె & $\frac{7}{6}$ & fं & $\stackrel{\sigma}{6}$ & कृ & $\stackrel{\overparen{\sigma}}{\sigma}$ \\
\hline & 芯 & $\stackrel{0}{2}$ & 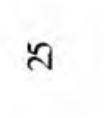 & $y$ & $\tilde{ت ี ~}$ & $\frac{\Delta}{\sim}$ & $\stackrel{9}{I}$ \\
\hline & 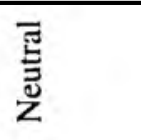 & ○ & $\vec{\infty}$ & $\stackrel{\circ}{2}$ & లి & $\cong$ & $\sqrt{2}$ \\
\hline & 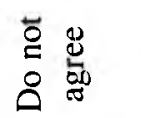 & $\stackrel{\infty}{-}$ & $\stackrel{\infty}{-}$ & $\stackrel{\circ}{\rho}$ & $\stackrel{\infty}{\sim}$ & $\stackrel{\infty}{\longrightarrow}$ & 0 \\
\hline & 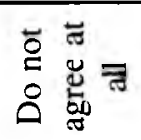 & $\vec{\pi}$ & 0 & $\stackrel{\circ}{\rho}$ & $\stackrel{\circ}{\dot{m}}$ & 0 & $\stackrel{\infty}{\longrightarrow}$ \\
\hline \multirow{5}{*}{ 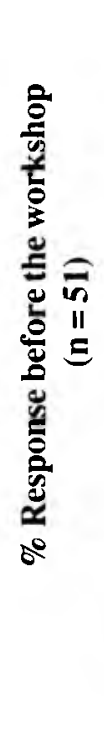 } & 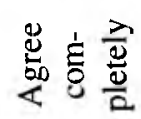 & $\stackrel{\stackrel{Y}{\exists}}{\exists}$ & तิ & $\frac{\dot{m}}{\mathrm{~m}}$ & $\overline{\vec{\sigma}}$ & જू & $\ddot{m}$ \\
\hline & 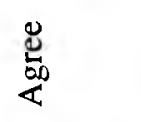 & $\stackrel{Q}{\Xi}$ & $\tilde{\nabla}$ & $\stackrel{\infty}{=}$ & $\stackrel{\sim}{\pi}$ & $\frac{0}{i}$ & $\stackrel{n}{\approx}$ \\
\hline & च & $\stackrel{\varphi}{\sim}$ & $\underline{\underline{n}}$ & $\frac{n}{\sqrt{n}}$ & $\stackrel{\circ}{\circ}$ & $\stackrel{\circ}{\sim}$ & $\stackrel{\circ}{9}$ \\
\hline & 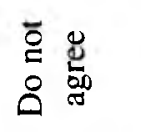 & $\stackrel{\infty}{\alpha}$ & 0 & $\stackrel{\circ}{\varrho}$ & $\vec{m}$ & $\stackrel{\infty}{=}$ & $\stackrel{\infty}{=}$ \\
\hline & 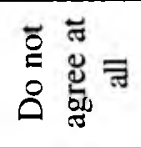 & ले & ஜे & $\stackrel{\infty}{\sim}$ & 0 & $\vec{m}$ & in \\
\hline 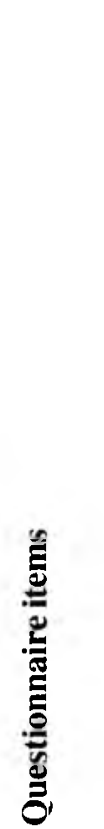 & & 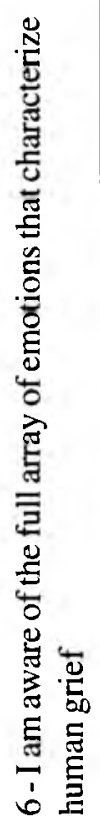 & 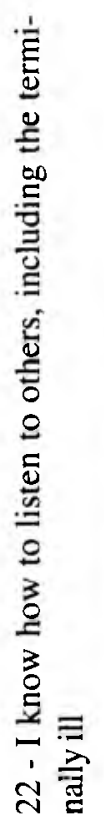 & 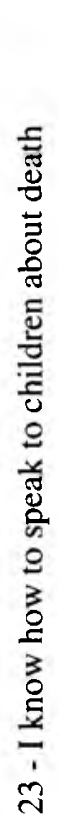 & 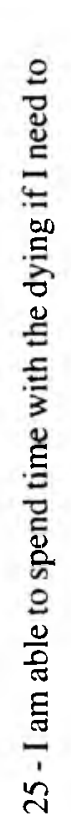 & 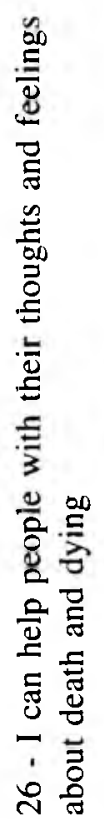 & 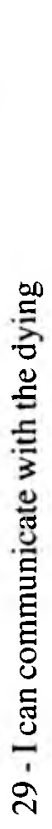 \\
\hline
\end{tabular}

the workshop there was a total of 328 neutral responses to the 30 items in the questionnaire. This means an average of 6 neutral responses per respondent. The highest number of neutral responses were to items;

- 8 - Ifeel prepared to face my own death (33.3\%)

9 - I feel prepared to face my own dying process $(33.3 \%)$

12 - Lately I find it OK to think about death $(27.5 \%)$

20 - I will be able to cope with future losses $(37.3 \%)$

23 - I know how to speak to children about death $(27.5 \%)$.

After the workshop there was a total of 237 neutral responses to the 30 items in the questionnaire, an average of 4 neutral responses per respondent. The highest number of neutral responses were to items;

- $\quad 8$ - I feel prepared to face my own death $(35.7 \%)$

9 - I feel prepared to face my own dying process $(30.4 \%$ )

It is interesting to note that in the case of item 8 (I feel prepared to face my own death), this number had increased after the workshop and that both of these items above refer to the respondents' own death.

\section{Death competency in dealing with self}

The objective of the workshop was to encourage the health workers to spend some time thinking about what death meant to them and how they felt about facing their own dying process. The death competency of the health workers in coping with themselves is reflected in Table 1. The nine items shown in this table dealt with the health workers' own death related issues and fears, and this table shows the items reflecting a marked change in the number of health workers who agreed with the statements before and after the workshop.

The subject of death is one that is usually avoided and health workers "being part of a society that fears, avoids, and denies death, share the same fears and attitudes about death as those they are called on to serve" (Jacik, 1989:257). Unless the health workers are able to work through their own issues about death and dying, they will not be able to efficiently help their clients, and "the counsellor may become the counselled" (Whittle, 1999:1). It has been men- 
tioned that nurses who are specifically educated to meet the needs of a dying client and their family are likely to reflect a positive attitude towards coping with death (Corr \& Doka, 1994:551).

\section{Education and preparation of nurses for coping with death}

There is a lack of relevant death education for nurses, which was demonstrated in a study by Cooke, Cooke \& Glucksman (1992:1207). These authors found in their survey of 78 Emergency Departments in England \& Wales that 44 of these departments indicated that increased training was needed in order to improve the care of the bereaved relatives. Flam (1999:97) supported this finding in a study carried out in Brussels, Belgium where the physicians and the nurses involved in the study commented that they had not been taught how to notify people of bad news in their basic training. In a phenomenological study carried out by Brysiewicz (2000:89) amongst emergency nurses in South Africa, it was highlighted that death education is missing from the basic nursing curriculum.

Death education, for example the proper identification of the stages of grief and the knowledge of appropriate interpersonal skills, will help the health workers in dealing effectively with the death of a client. This would lead to a reduction in death anxiety and lessen the development of stress disorders amongst these professionals (Wheeler, 1996:30). Tye (1993:955) suggests that training should be provided which focuses on psychosocial and interpersonal skills as well as exploring ones own experiences and attitudes about death and dying - and that doctors as well as nurses need to be involved.

\section{Death competency in dealing with significant others}

Table 2 shows the responses of the workshop participants with regards to death competency in coping with the significant others, that is, the client's family and friends. The items shown in this table illustrate how after the workshop the respondents felt more able to cope with the significant others, thus suggesting that the workshop had provided them with the necessary information. This table shows the items reflecting a marked change in the number of health workers who agreed with the statements before and after the workshop. Dealing with the family of a client who has died is very difficult, emotionally draining and overwhelming. There is no time to prepare the family for the loss and they seldom have past experiences upon which to draw to enable them to cope. The death of their loved one is often their first experience with death. The family needs to have health professionals who are able to empathise with them as this will make a lasting impression that will help towards emotional healing (Waters, 1987:46).

\section{Avoiding death}

Emergency nurses have been shown in a study done by Payne, Dean \& Kalus (1998:705) to be more likely to avoid thinking about death and showed greater fear and less acceptance of death than hospice nurses. One reason for this may be that the emergency nurses are unprepared for death and the handling of the client and their family. Health workers with a high level of death anxiety are more likely to use "avoiding" coping strategies (Payne et al, 1998:705). These health workers cope with the situation by avoiding it (either physically or emotionally), thus not having to come face to face with death and deal with their emotions. Many health workers are left with feelings of failure if despite all their interventions the client dies (Jacik, 1989:262).

\section{Dealing with children and death}

Item 23 of the questionnaire (see Table 2) refers to the respondent's ability to speak to children about death. Less than half the respondents agreed that they were able to speak to children about death before the workshop, as compared with $71.4 \%$ who agreed after the workshop. It is difficult for adults to talk to children about death as there is the urge to protect the child, that "they are too young to understand" or "they don't need to know about that, not yet". It is however important to remember that children are very perceptive and will know that something is wrong and will then be frightened by a lack of knowledge (Wright 1996:64). When speaking to children about death, it is very important to be honest and to explain in such a way that they can understand. Questions need to be answered and opportunities made to allow children to express their feelings (Iserson, 1999: 137-138).

Helping the families who have lost a loved one can be challenging although by understanding their needs and keeping ones death skills up to date, it can be extremely rewarding both personally and professionally (Wheeler, 1996:30).

\section{Limitations of the study}

A limitation to the study was that the workshops were originally developed for registered nurses to attend although due to the interest expressed by other health workers the sample then included health workers from diverse fields. This then posed a problem with the questionnaire as there were a variety of educational qualifications amongst the workshop participants and for some the language in the questionnaire was difficult to understand. For this reason some of the respondents chose not to complete the questionnaire a second time as they found it time consuming on the first occasion. Due to the small sample size the results of this study cannot be generalised.

\section{Recommendations}

For future research the questionnaire should be modified to ensure easy interpretation of the language used, and 
possibly translated into Zulu. The sample size could be increased and the research carried out in another district in KwaZulu-Natal. Recommendations for practice are that efforts be made to get health workers to explore their own thoughts and feelings concerning death and to educate them about best ways of coping with bereaved families and themselves.

\section{Conclusion}

Given the frequency with which health workers are expected to cope with death and the bereaved families, it is essential that management is sensitive to their needs. This sensitivity is necessary for the health and well being of the worker as well as for the care of the dying and the bereaved. These short workshops demonstrated the benefits to health workers in addressing their needs. Management and educators need to take cognisance of the words of Coolican (1994,611) who states that "patients die only once, we need to make it the best death it can be.... for the patient, the family and the caregiver".

\section{References}

BRYSIEWICZ, P 2000: Exploring the trauma care nurses lived experiences of dealing with the violent death of their clients. Unpublished Masters Dissertation. Durban: University of Natal.

COOKE, MW; COOKE, HM \& GLUCKSMAN, EE 1992 : Management of sudden bereavement in the accident and emergency department. British Medical Journal. 304, 1207 1209.

COOLICAN, MB 1994: Families facing the sudden death of a loved one. Critical Care Clinics of North America. 6(3), 607-612.

CORR, CA \& DOKA, KJ 1994: Currents Models Of Death, Dying, And Bereavement. Critical Care Clinics of North America. 6(3), 545-552.

FLAM, R 1999: Helping the Bereaved at the Emergency Department: A Study at the Brussels University Hospital. International Journal of Trauma Nursing. 5, 95-98.

ISERSON, KV 1999: Grave Words. Notifying Survivors about Sudden, Unexpected Deaths. Tucson: Galen Press.

JACIK, M 1989: Spiritual Care of the Dying Adult. In: Carson, VB Spiritual Dimensions of Nursing Practice. Philadelphia: Harcourt Brace \& Company.

MEDICAL RESEARCH COUNCIL (MRC) 2000: TB and HIV - the deadly duo. MRC News. 31(3), 21-22.

MEUMANN, C \& PEDEN, M 1997: National Trauma Research Programme (NTRP) of the South African Medical Research Council. The Durban metropolitan pilot study. Trauma Review. 5 (1), 1 - 8 .
NEIMEYER, RA 1994: (ed) Death Anxiety Handbook. Research, Instrumentation and Application. Washington: Taylor \& Francis.

NEIMEYER, RA 1997-98: SPECIAL ARTICLE: Death Anxiety Research: The State of the Art. OMEGA. 36(2), 97-120.

PAYNE, SA; DEAN, SJ \& KALUS, C 1998: A comparative study of death anxiety in hospice and emergency nurses. Journal of Advanced Nursing. 28(4). 700 - 706.

ROBBINS, R.A. 1994: Death Competency: Bugen's Coping with Death Scale and Death Self-Efficacy. In Neimeyer, RA (ed) Death Anxiety Handbook. Research, Instrumentation and Application. Washington:Taylor \& Francis.

TYE, C 1993: Qualified nurses' perceptions of the needs of the bereaved family members in the accident and emergency department. Journal of Advanced Nursing. 18, 948-956.

VAN DER SPUY, J 1998: South African Road Traffic Trauma: Where Are We Heading? Trauma Review. 6(3), 1-3 $\& 12$.

VENTER, PR 1998: Children in traffic - vulnerable road users. Trauma and Emergency Medicine. 17(1), $10 \& 12$.

WHEELER, HH 1996: A review of nurse occupational stress research. British Journal of Nursing. 6(11), 642-645.

WHITTLE, B 1999: Grief in nursing: Denial \& depression. [16 paragraphs]

Available at: hppt: //www.lis.net.au/ bwhittle/essay.html.

WRIGHT, B 1996: Sudden Death. A Research Base For Practice. London: Churchill Livingstone.

WATERS, V 1987: First impressions of grief. Nursing Times. February 4, 46-47. 